\title{
El rol de las agronomías y acopios en la consolidación del modelo de agronegocios en Balcarce (2000 - 2019)
}

The role of agronomies and cereal traders in the consolidation of the agribusiness model in Balcarce (2000-2019)

\author{
Mariana Paola Bruno \\ Instituto de Innovación para la Producción Agropecuaria y el Desarrollo \\ Sostenible (IPADS-Balcarce), Argentina \\ Grupo de Estudios sobre Población y Territorio. Facultad de \\ Humanidades. Universidad Nacional de Mar del Plata, Argentina \\ marian_bruno@hotmail.com
}

\author{
Maria Laura Viteri \\ Area de Economía y Sociología Rural EEA INTA Balcarce, Argentina \\ Instituto de Innovación para la Producción Agropecuaria y el \\ Desarrollo Sostenible (IPADS-Balcarce), Argentina \\ viteri.maria@inta.gob.ar
}

\author{
Marcelo Sili \\ CONICET. Departamento de Geografia y Turismo. \\ Universidad Nacional del Sur, Argentina \\ sili.marcelo@gmail.com
}

\section{ReSUMEN:}

El objetivo de este trabajo es reflexionar sobre el rol de las agronomías y acopios en la construcción social del territorio de Balcarce (sudeste bonaerense) a partir del año 2000. Para ello, se focaliza en las interacciones entre lo global y local, a través de entrevistas semiestructuradas a responsables de empresas, empleados e informantes calificados. Se concluye que los distribuidores de agroinsumos son clave en la organización de los sistemas productivos locales. Las prácticas e interacciones entre los diferentes actores de este ensamblaje colaboran en la construcción de un espacio de control y disciplinamiento al comando de las empresas transnacionales.

Palabras clave: Agroinsumos, Empresas Transnacionales, Interacciones, Territorio.

\begin{abstract}
:
The aim of this research paper was to reflect upon the role of agronomies and cereal traders in the social construction of Balcarce territory (Southeast of Buenos Aires province) since the year 2000. It focused on the interactions between global and local practices. After having carried out and analysed semi-structured interviews to company managers, employees and qualified informants, it was concluded that agricultural supply distributors are key in organizing local production systems. The practices and interactions among the different actors of this assemblage collaborate in the construction of a space of control and discipline under the command of transnational companies.
\end{abstract}

KEYWORDS: Agro-inputs, Transnational companies, Interactions, Territory. 


\section{INTRODUCCIÓN}

A partir de los años 90, en la Argentina se produjo un fuerte cambio tecnológico en el sector agropecuario, caracterizado por el pasaje de una agricultura basada en un sistema de labranza convencional y con menor utilización de insumos industrializados, a una agricultura con una mayor utilización de semillas mejoradas, agroquímicos y nuevas prácticas como la siembra directa. Bajo el nuevo modelo productivo dominante se reconfiguraron las relaciones entre los diferentes sujetos sociales. Los productores agropecuarios dejan de controlar todos los factores de producción (tierra, capital y trabajo), y pasan de relacionarse con actores mayormente locales a conformar redes cada vez más globales (Bisang, Anlló, Campi y Albornoz, 2009; Teubal, Domínguez y Sabatino, 2005). El nuevo modelo productivo, llamado agronegocios o agribusiness (Gras y Hernández, 2013), se inscribe bajo el paradigma cientifico-técnico-informacional (Santos 1996, 2000), en el cual la tecnología se hace inseparable de la ciencia y la información.

Dentro de este contexto, las Empresas Transnacionales (ET) de agroquímicos y semillas tienden a localizar las etapas productivas de las cadenas de valor en diferentes territorios según las ventajas ofrecidas por cada uno. En este sentido, los territorios se convierten en una porción del espacio global, donde se expresa la globalización y cuyo funcionamiento está condicionado por su relación con otros territorios. El resultado es una jerarquización espacial de lugares: del mandar, donde las empresas concentran las decisiones y las principales actividades de Innovación y Desarrollo $(\mathrm{I}+\mathrm{D})$; del hacer, donde se lleva a cabo la producción, y los espacios marginados (Santos, 1996).

Las ET de agroinsumos instalan sus casas matrices en grandes ciudades, principalmente de Estados Unidos y de algunos países europeos y asiáticos. En estas sedes centrales se toman las decisiones, se desarrolla la innovación y se controla la circulación (comercialización y distribución) de productos y la gestión del capital (Santos, 1997). Estas ciudades se convierten en unos de los principales lugares del mandar, pues acumulan información y comandan los procesos productivos. La concentración no sólo se da en el nivel territorial sino también en el intersectorial. Mediante fusiones entre grandes empresas y adquisiciones de nuevas unidades comerciales se conforman grandes corporaciones que aglutinan los negocios de la química, la agroquímica, la producción de semillas, desarrollos biotecnológicos y la industria farmacéutica, con lo que se concentra cada vez más el mercado de agroinsumos (Romero, 2014). En los últimos años, el poder de estas corporaciones se fortalece al celebrar acuerdos y alianzas con las ET de maquinaria agrícola y del mundo digital (RedAgrícola, 2019; Grupo ETC, 2019).

En los lugares de la producción o del hacer confluyen las racionalidades establecidas por las ET y el accionar de los actores que operan localmente, bajo una relación dialéctica, dinámica e inestable entre lo local y lo global (Santos, 1997). En estos lugares, el agronegocio (Gras y Hernández, 2013) se desarrolla reconfigurando la trama de actores agrarios (productores, pool de siembra, grandes empresas agropecuarias, rentistas, contratistas, distribuidores y comercializadores de agroinsumos y granos). Las agrociudades, que surgieron durante el período de la modernización agropecuaria en los años 60 como lugares de sociabilidad de los productores y sus familias, se consolidan como centros de servicios regionales albergando a empresas de acopios, comercios de venta de insumos, estaciones de servicios, productores modernos clásicos, y en algunos casos pueden complementar sus actividades con la instalación de una agroindustria (Albaladejo, 2013).

El comportamiento y la dinámica de las ET tiene un claro impacto en los territorios rurales de la Argentina, territorios que claramente se comportan como un lugar para el hacer. En efecto, en la Argentina las ET de agroinsumos han modificado sus sistemas de comercialización, lo que afecta los modos de circulación de los productos y las formas de relación entre los actores (Hernández, 2015). Una de las primeras firmas fue Monsanto (principal vendedora de semillas transgénicas en el mundo, hoy comprada por Bayer), que desarrolló estrategias de comercialización y expansión territorial instalando centros de servicios que integran la venta de semillas e insumos con el asesoramiento a productores. El desarrollo de una red de centros de servicios de venta exclusiva fue logrado por las ET al absorber varias de las antiguas agronomías locales 
que vendían productos de distintas marcas, así como también interesando a participar de la red, con una agronomía, a técnicos comerciales referentes en el territorio (Gras y Hernández, 2013). Sucesivamente, esta modalidad fue adoptada por las ET competidoras (Carabajal, 2013; Hernández, 2015).

Posteriormente, fueron surgiendo otras modalidades, como la conformación de Joint Venture entre ET e inversionistas privados locales con el fin de expandirse territorialmente en número de sucursales y localizarse en proximidad de los productores (Zavaleta, 2014). Asimismo, empresas -que se iniciaron como acopiadoras y comercializadoras de granos en localidades del interior de la Provincia de Buenos Aires-, fueron incorporando diversas estrategias de expansión comercial y territorial, como la venta de agroinsumos, e instalaron agronomías en diferentes ciudades (Bassi, Iorio y Cendón, 2011). Algunas de estas firmas llegaron a constituirse en megaempresas agropecuarias, como es el caso de Los Grobo (Sosa, 2017). Las formas de comercialización y distribución de innovaciones biotecnológicas y químicas, así como el sistema de distribución en red, los Joint Venture y las megaempresas agropecuarias, coexisten en los territorios del hacer y transforman las relaciones entre las ET, las agronomías y los productores.

El objetivo de este trabajo es reflexionar sobre el rol que cumplen las empresas prestadoras de servicios (acopios y agronomías) en el partido de Balcarce (sudeste bonaerense) en la articulación entre lo global y lo local, así como sus lógicas de inserción territorial a partir del año 2000. La hipótesis que subyace a esta investigación es doble. En primer lugar, se afirma que las agronomías y acopios instalados en el territorio de Balcarce son claves para la organización de los sistemas productivos locales, ya que definen el régimen técnico y las formas de producción, y por ende la dinámica de desarrollo del territorio. En segundo lugar, se asevera que las agronomías y acopios han sido capturados y/o condicionados por las lógicas de las ET, las cuales pueden ahora comandar en forma directa o indirecta el proceso productivo vía estas empresas locales; así, la organización de la producción se lleva a cabo bajo una dependencia, cada vez mayor, de las ET y de las lógicas de los mercados globales comandados por éstas.

Para este trabajo las agronomias son definidas como comercios a cargo de profesionales del agro (ingenieros agrónomos o especialistas en comercio agrario) que venden semillas y agroquímicos (fertilizantes, insecticidas, herbicidas) y asesoran a sus clientes en los modos de aplicación y otras técnicas. Los acopios o cerealeras son empresas que proveen gran capacidad de almacenamiento y acondicionamiento de granos, aseguran la logística para la movilización de la producción y ponen a disposición de los clientes diferentes herramientas para la comercialización de granos (Cauhèpè y Gutheim, 2013). Es importante destacar que los acopios han ido incorporando la venta de agroquímicos como parte del servicio prestado a sus clientes.

Desde sus orígenes (1876), Balcarce es una ciudad estrechamente vinculada al sector agropecuario, que refleja dinámicas globales y transformaciones en la interacción entre el mundo rural y urbano. Esta agrociudad es una de las 20 localidades argentinas con mayor número de sucursales de empresas líderes en agronegocios vinculadas a la producción y comercialización de agroinsumos y el acopio y comercialización de granos (Maldonado, 2019). Su dinámica expansiva en cultivos como papa, trigo, soja, girasol y maíz fue acompañada por empresas de venta de maquinarias, reparación mecánica, contratistas, laboratorios de análisis de suelo y agua, embolsadoras, acopios, agronomías, galpones de empaque, etc.

A través de entrevistas en profundidad a informantes clave y dueños o representantes comerciales de empresas instaladas en el partido de Balcarce, se explora la compleja trama que involucra a las agronomías y acopios radicados en este espacio con impronta agroalimentaria.

Este artículo se organiza de la siguiente manera. En la primera sección se exponen las nociones teóricas y la metodología utilizada para analizar y comprender el terreno del hacer, desde las estrategias de las ET y el rol de las agronomías y acopios en Balcarce. En la segunda parte se caracteriza a las agronomías y acopios relevados en el trabajo de campo. La tercera sección estudia las estrategias comerciales de las ET para captar mercado en su interacción con las agronomías y acopios locales. El cuarto apartado estudia cómo las lógicas de las ET se trasladan a los productores por intermedio de las prácticas de captación y fidelización que desarrollan los técnicos comerciales de las agronomías y acopios entrevistados. Por último, se reflexiona acerca del rol de 
estas empresas en la intermediación entre las racionalidades de las ET y la complacencia de los productores locales (Santos, 1997).

\section{Aspectos teóricos-Metodológicos}

Para comprender el rol de las agronomías y acopios en la interacción entre las lógicas globales, establecidas desde los lugares del mandar, y las prácticas locales y cotidianas desde las zonas agropecuarias del hacer, se toma el caso de la ciudad de Balcarce, cabecera de partido. Este trabajo toma la noción de territorio como una construcción social, cargado de un conjunto de intencionalidades políticas, sociales, productivas, culturales, económicas que se plasman o concretan en función de las capacidades de los actores para llevarlas a cabo. En el territorio de Balcarce convergen las acciones de múltiples actores (agronomías, acopiadores, agrónomos, productores, contratistas, servidores públicos, universidades, municipio, etc.) que interactúan constantemente dentro y fuera del espacio geográfico delimitado políticamente (Massey, 2012; Sili, 2018). Este ensamblaje de actores y artefactos (De Landa, 2006) construye y transforma el territorio de Balcarce a partir de sus prácticas y resignificaciones. Buscando salir de los dualismos entre global/local, micro/macro, local/externo, virtual/ físico, experto/inexperto, se focaliza en las interacciones sociales en las que un mismo actor responde a lo global y local en un mismo momento. Estas interacciones serán explicadas a partir de las nociones de horizontalidades y verticalidades (Santos 1996, 2000; Silveira, 1997).

Las verticalidades corresponden a los flujos de información, tecnologías, mercancías y recursos financieros que conectan diferentes lugares y aseguran el funcionamiento global de la sociedad y la economía. Se crean solidaridades y jerarquías entre lugares distantes, por medio de órdenes técnicas, financieras y políticas. Las verticalidades son los vectores de una racionalidad superior y hegemónica que generan un orden de lo cotidiano y de la obediencia (Santos, 2000). En el caso analizado, los flujos materiales e inmateriales que circulan entre las ET y las agronomías y acopios instalados en el territorio son los vectores que conectan a Balcarce con el sistema mundo. Esto se observa a través de las diferentes estrategias de las ET.

En cambio, las horizontalidades se interpretan como el escenario de las relaciones cotidianas entre individuos, grupos e instituciones locales y globales. Es el lugar de la finalidad impuesta desde el exterior, donde la complacencia emerge a partir de la conformación de alianzas estratégicas entre los diferentes actores sociales. Estas asociaciones actúan como dispositivos de poder, legitimadoras del modelo dominante (Santos, 2000; Córdoba, 2014). Pero también son el ámbito donde mejor se pueden observar las relaciones de conflicto y la resistencia al orden establecido (Santos, 2000). En este sentido, las prácticas presentes entran en contradicción con las rugosidades del pasado, y requieren de nuevas traducciones y alianzas que viabilicen el modelo productivo, lo que da lugar a una metamorfosis del espacio habitado (Santos, 1996).

En síntesis, las horizontalidades y verticalidades sirven para explicar tanto las prácticas que surgen desde las lógicas globales como sus traducciones territoriales. En este sentido, el territorio de Balcarce se constituye como un ensamblaje de verticalidades y horizontalidades, del que las estrategias de las agronomías y acopios forman parte (De Landa, 2006).

Metodológicamente, el trabajo se sustenta en técnicas principalmente cualitativas. En primer lugar, se elaboró una base de datos ad hoc para identificar a las empresas proveedoras de bienes y servicios al agro instaladas en Balcarce. Los datos recabados provienen de diferentes fuentes secundarias (Dirección de Recursos y Secretaría de Producción de la Municipalidad de Balcarce, Cámara de Comercio e Industria de Balcarce y Fundación Lucha Contra la Fiebre Aftosa). Además, se registró a las empresas presentes en distintas exposiciones locales (Educo Agro 2016, Expo Rural Balcarce 2017), así como a las empresas instaladas en las avenidas principales de la ciudad. La base se completó con entrevistas semiestructuradas a informantes calificados del sector público (10) y privado (6), y con la revisión de sitios web. Se obtuvo un listado de 110 empresas que ofrecen bienes y servicios para el agro (venta y reparación de maquinarias, acopiadores, laboratorios de análisis técnicos en suelo, venta de insumos y asesoramiento técnico, venta de 
implementos de riego, etc.). No se incluyeron los contratistas en la base de datos, dado que se relevarán en una segunda etapa de la investigación. Tomando como referencia la Clasificación Nacional de Actividades Económicas (INDEC, 2010), se categorizó el listado en función de su rama de especialización dentro de las llamadas empresas de bienes y servicios para el agro. Este trabajo se focaliza en las empresas que participan en la venta de agroinsumos (semillas, agroquímicos y fertilizantes) o en la comercialización de granos: agronomías $\mathrm{y}$ acopiadores.

En segunda instancia, a partir de la base de datos, se contactó y entrevistó a los representantes de las firmas (agronomías y acopios cerealeros) y se indagó en sus prácticas organizacionales y comerciales. Sobre un total de 24 empresas dedicadas al rubro seleccionado, fueron entrevistadas siete (7) entre los meses de junio de 2018 y junio de 2019. Se indagó sobre la trayectoria y los orígenes de la empresa, su principal actividad dentro del rubro, tipo de bienes y servicios que ofrece, cómo se relacionan con proveedores, clientes e instituciones públicas y privadas, así como su zona geográfica de influencia laboral y comercial. La información obtenida fue sistematizada y analizada teniendo en cuenta las siguientes dimensiones: características generales de las empresas, las relaciones que se establecen entre las agronomías y las ET que determinan el ámbito de las verticalidades, y la relación entre las agronomías y los clientes para delimitar el escenario de las horizontalidades. Si bien las horizontalidades y verticalidades fueron analizadas en distintos apartados, esto responde sólo a fines analíticos, ya que ambas confluyen en el territorio e interactúan constantemente. Cada dimensión fue rescatada de acuerdo con las visiones de los actores involucrados en la actividad (Long, 2007).

\section{Caracterización de las agronomías y acopios en BalCarce (2000 - 2019)}

El partido de Balcarce, al estar conectado con centros regionales de mayor relevancia como Mar del Plata, Tandil y Necochea por la Autovía Nacional No 226 y la Ruta Provincial No 55, adquiere una posición estratégica a nivel regional. A esto se suma su potencialidad productiva y la presencia de profesionales especializados, lo que hace de Balcarce un lugar-territorio (Saquet, 2015) interesante para las ET de agroquímicos que desean expandir sus mercados.

Las condiciones agroecológicas de la zona han permitido el desarrollo del sector agropecuario, en el que se amalgaman producción de granos (trigo, soja, girasol y maíz), hortalizas (principalmente papa) y ganadería. El Gráfico 1 representa la evolución de la superficie sembrada en el partido de Balcarce con los principales cultivos. Siguiendo la tendencia a nivel nacional, se observa un incremento exponencial de la superficie sembradacon soja a partir de la campaña 1996/97 (desregulación del mercado de soja genéticamente modificada), quealcanzó las 131.900 ha en la campaña 2012/13, año en el que la oleaginosa cotizaba a 646 U\$S/tn (Fernández Martínez, 2018). A partir de 2014/15, la caída de los precios internacionales para esa oleaginosa permitiórecuperar tímidamente para Balcarce la superficie destinada a cultivos tradicionales (trigo, maíz, girasol).

El partido forma parte de una de las principales regiones productoras de papa del país. El sudeste bonaerense aporta el $45 \%$ del volumen de producción de papa a nivel nacional y el $90 \%$ para la provincia (Mosciaro, 2011). La radicación de una multinacional procesadora de papas prefritas supercongeladas, a mediados de los 90, revolucionó las formas de producir y comercializar papa en la zona. Con el objetivo de garantizar la cantidad y la calidad requerida por la industria, los productores fueron incorporando innovaciones tecnológicas como la introducción de nuevas variedades de semillas, el riego por pivote central, la mecanización de las labores y el uso más intensivo de agroquímicos; se trata de uno de los cultivos que mayor cantidad de aplicaciones conlleva. Las principales innovaciones vienen de la mano de los contratos que se celebran entre el productor y la industria, en los que se acuerdan el precio, la calidad, cantidad y fecha de entrega. Los cambios en el manejo del cultivo y en las formas de almacenamiento, entre otros aspectos, dieron lugar a la emergencia de nuevos proveedores de bienes y servicios (monitoreo de control de plagas y 
enfermedades, laboratorios de fertilidad del suelo, contratistas de labores, servicios de acondicionamiento y almacenamiento) (Mateos, 2003; Bruno, Mujica, Cendón y Viteri, 2018).

\section{GRÁFICO 1}

Evolución de la superficie sembrada (ha) con los principales cultivos en el partido de Balcarce. Campañas 1990-2019

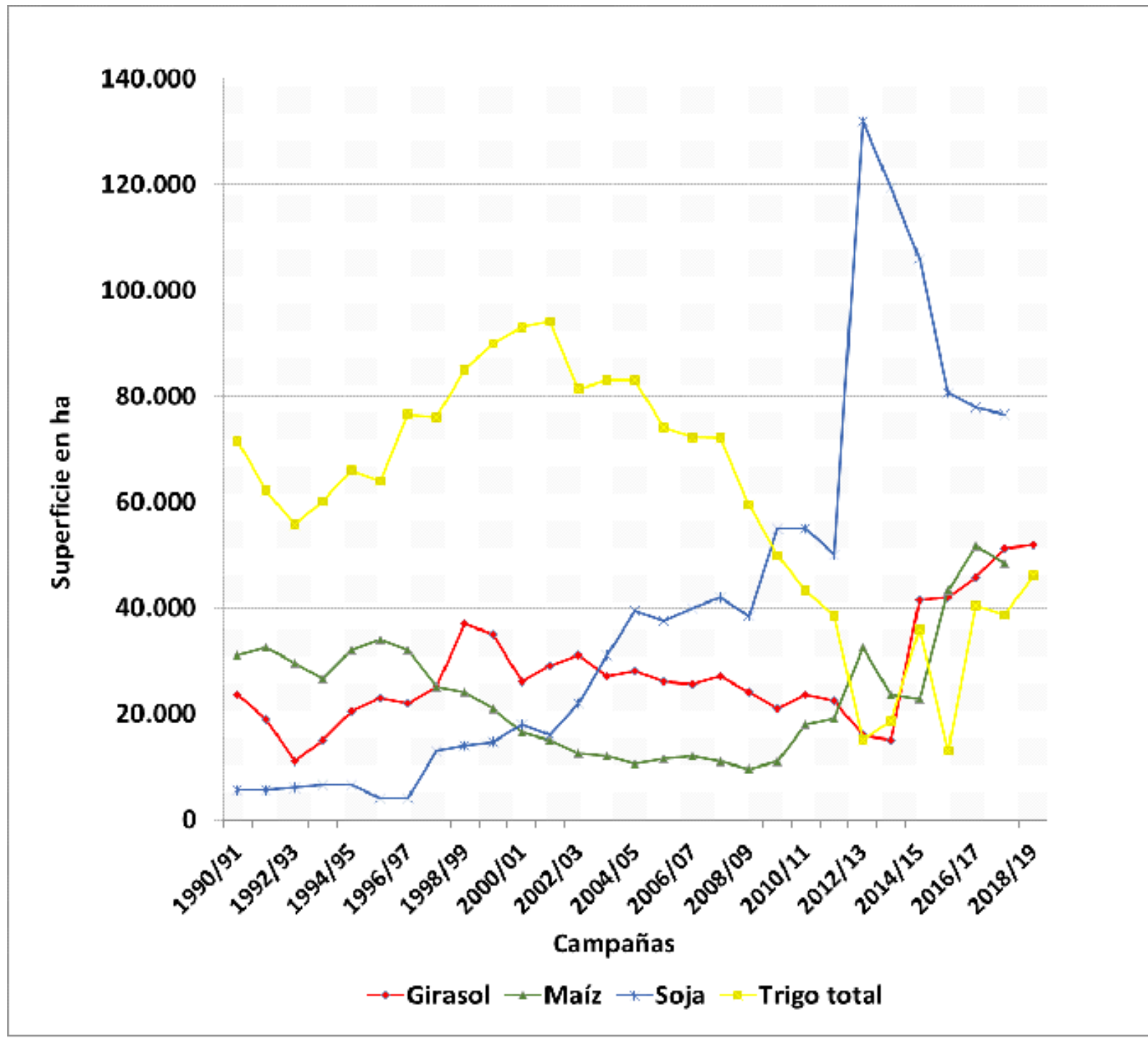

Fuente: Elaboración propia sobre la base de la Dirección de Estimaciones Agrícolas y Ganaderas [Fecha de Consulta: 14 de febrero 2017] y de la Dirección Provincial de Estadísticas, Gobierno de la Provincia de Buenos Aires [Fecha de consulta: 7 de febrero 2020]

El incremento de la producción de granos y otros cultivos viene asociado al uso cada vez más intensivo de agroquímicos y a la adopción de nuevas formas de organización de la producción. Estas transformaciones en el sector agropecuario son acompañadas por la proliferación de proveedores de agroinsumos, filiales de empresas extranjeras fitomejoradoras, instituciones financieras, industrias de transformación, que desde mediados de los 90, al igual que en otras localidades de la región pampeana (Finola y Maldonado, 2017), se instalan en la ciudad.

En el caso particular de Balcarce, la producción agropecuaria se ve potenciada por un entramado institucional público-privado en el cual se destacan la Estación Experimental del Instituto Nacional de Tecnología Agropecuaria (EEA-INTA Balcarce) y la Facultad de Ciencias Agrarias de la Universidad Nacional de Mar del Plata (FCA-UNMdP). Estas instituciones no sólo se dedican a investigar y formar 
profesionales sino que también prestan servicios a productores sobre diagnóstico de enfermedades en cultivos, análisis de suelos, entre otros, compitiendo con oferentes privados. En los años 90, la actividad de estas instituciones se vio mermada por el recorte presupuestario que sufrió todo el sistema nacional de ciencia y técnica. Paralelamente, las multinacionales favorecidas por las políticas aperturistas fueron consolidando su posicionamiento en el país en lo referido al desarrollo en biotecnología. Si antes el INTA tenía un rol destacado en el desarrollo de variedades híbridas, ahora son las empresas multinacionales las que lideran la innovación y producción en biotecnología. Como estrategia de supervivencia, los investigadores del INTA debieron salir a prestar servicios y establecer alianzas con las multinacionales (Gras y Hernández, 2013; Romero, 2014; Maldonado, 2019).

MAPA 1

Localización de las agronomías y acopios en el partido de Balcarce (2018)

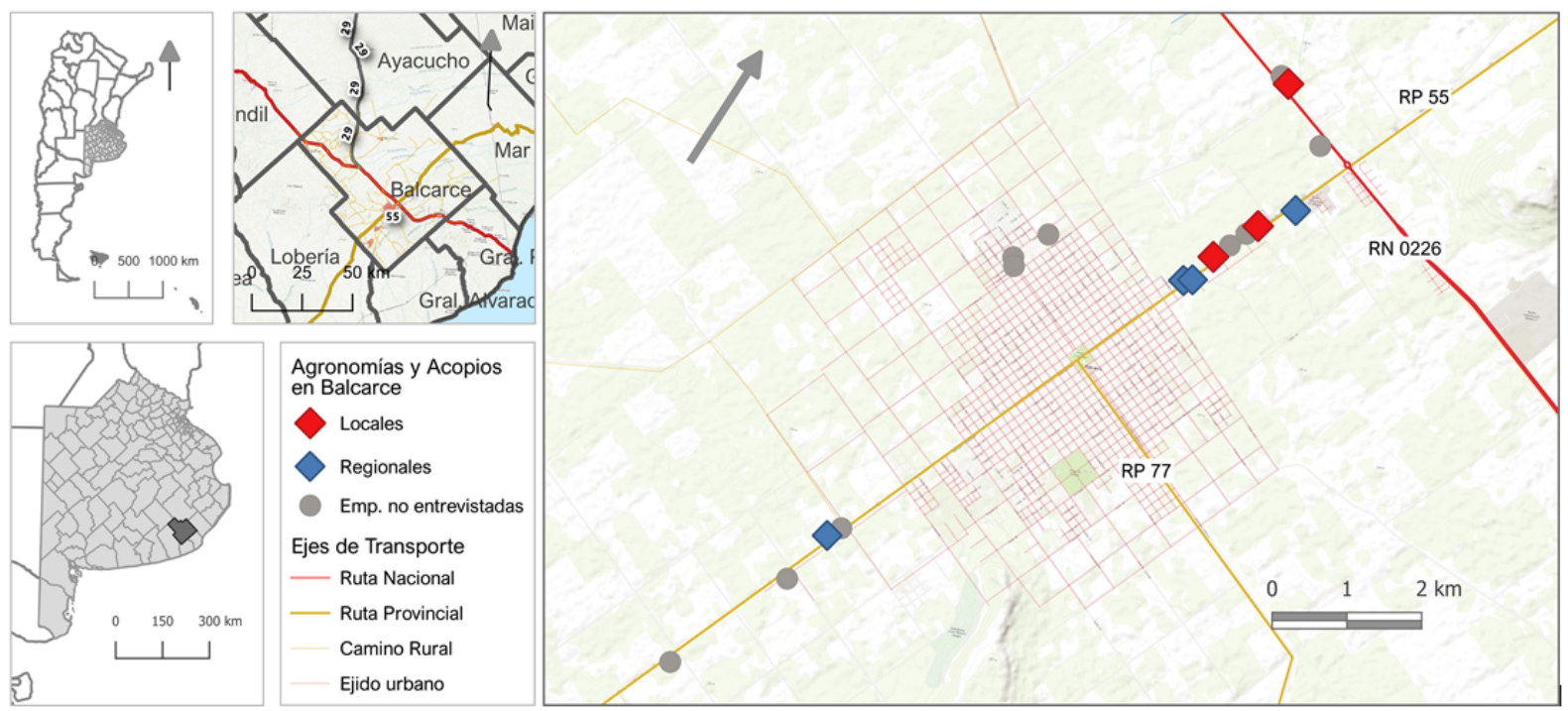

Fuente: Elaboración personal sobre la base de sitios web consultados y entrevistas realizadas entre junio 2018 y junio 2019. Cartografía INDEC 2010

Del total de las 110 empresas orientadas al agro radicadas en Balcarce e identificadas en la base de datos, las agronomías y acopios representan el $22 \%$ (Bruno, Viteri y Sili, 2018). ${ }^{1}$ Como se puede observar en el Mapa 1 , estas empresas se encuentran localizadas principalmente en las avenidas y vías de circulación de acceso a la ciudad cabecera del partido.

En la Tabla 1 se presentan las principales características de las agronomías y acopios localizados en Balcarce 
TABLA 1

Agronomías y acopios en Balcarce: características generales (2018/2019)

\begin{tabular}{|c|c|c|c|c|c|c|}
\hline $\begin{array}{l}\frac{\mathfrak{y}}{4} \\
\text { 흘 } \\
\text { w }\end{array}$ & 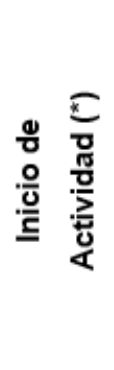 & 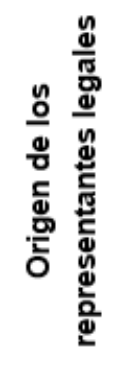 & 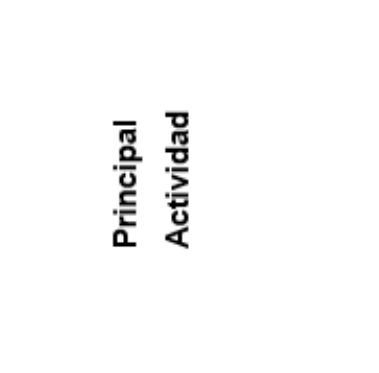 & 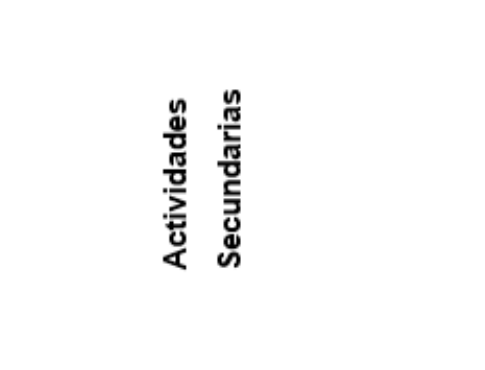 & 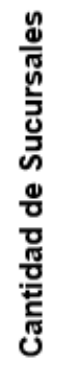 & 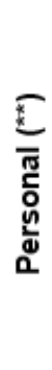 \\
\hline I & 1998 & Local & $\begin{array}{c}\text { Venta } \\
\text { agroinsumos }\end{array}$ & $\begin{array}{c}\text { Asesoramiento - } \\
\text { Producción de Granos - } \\
\text { Producción de Semillas }\end{array}$ & 1 & 8 \\
\hline II & 2011 & Local & $\begin{array}{c}\text { Venta } \\
\text { agroinsumos }\end{array}$ & $\begin{array}{c}\text { Logística - } \\
\text { Asesoramiento }\end{array}$ & 1 & 8 \\
\hline III & 2004 & Local & $\begin{array}{c}\text { Venta } \\
\text { agroinsumos }\end{array}$ & $\begin{array}{c}\text { Asesoramiento- } \\
\text { producción de semillas }\end{array}$ & 1 & 10 \\
\hline IV & 2006 & Regional & $\begin{array}{c}\text { Venta } \\
\text { agroinsumos }\end{array}$ & $\begin{array}{c}\text { Logística - } \\
\text { Asesoramiento - } \\
\text { Multiplicación de Semillas }\end{array}$ & 8 & 10 \\
\hline V & 2006 & Regional & $\begin{array}{c}\text { Acopio y comercialización de } \\
\text { granos }\end{array}$ & $\begin{array}{l}\text { Venta agroinsumos - } \\
\text { Producción de Granos - }\end{array}$ & 5 & 2 \\
\hline VI & 2009 & Regional & $\begin{array}{c}\text { Acopio y comercialización de } \\
\text { granos }\end{array}$ & $\begin{array}{c}\text { Venta agroinsumos - } \\
\text { Asesoramiento técnico y comercial - } \\
\text { Siembras Asociadas - } \\
\text { Acondicionamiento de semillas }\end{array}$ & 15 & 9 \\
\hline VII & 2014 & Regional & $\begin{array}{c}\text { Acopio de granos y venta de } \\
\text { agroinsumos }\end{array}$ & Servicios & 29 & 8 \\
\hline
\end{tabular}

Fuente: Elaboración propia sobre la base de entrevistas realizadas entre junio de 2018 y junio 2019

$\left({ }^{*}\right)$ Inicio de Actividad en Balcarce

$\left.{ }^{* *}\right)$ Se incluye sólo el personal de la sucursal de Balcarce.

Respecto del origen de estas empresas, es un sector que ha adquirido gran dinamismo durante los últimos treinta años a partir del cierre de viejas agronomías, adquisiciones por parte de nuevos actores, escisiones de socios, llegada de nuevos actores al mercado. Si bien la base de datos sólo contempla las empresas que se encuentran en actividad para el año 2018, la Tabla 1 permite realizar una aproximación a la dinámica empresarial reciente. De las siete firmas entrevistadas, sólo una de ella inicia sus actividades en la década del 90. El resto comienza a operar en Balcarce en la década del 2000, período en el cual el modelo de agronegocios se consolida (Gras y Hernández, 2013) y se incrementa la demanda mundial de commodities (Gorenstein y Ortiz, 2016). Varias de estas empresas surgen como nuevas a partir de ingenieros agrónomos, exempleados de agronomías radicadas en Balcarce con larga trayectoria (4). El resto de las firmas comienza su actividad en la ciudad adquiriendo agronomías tradicionales (1) o alquilando infraestructura preexistente (2). En estos últimos casos los antiguos negocios cerraron sus puertas y la infraestructura fue adquirida por terceros, quienes ceden las instalaciones en alquiler a las nuevas agronomías y/o acopios.

$\mathrm{Al}$ considerar el origen de los representantes legales de las firmas entrevistadas se pueden reconocer dos perfiles de empresas, que para este trabajo se han denominado locales y regionales (Tabla 1). Las agronomias locales surgen a partir de ingenieros agrónomos con fuerte arraigo local por haber nacido en Balcarce, 
ser egresados de la UNMdP y haber acumulado experiencia en el rubro. Las agronomías locales buscan consolidarse en el territorio representando de manera exclusiva a una marca líder a nivel mundial (Basf, Bayer-Monsanto, Syngenta-ChemChina, Corteva-DuPont y Dow Agro Science). Uno de los entrevistados comenta:

“A mí, que me tocó estar con [Empresa X de semillas], que era un producto que nadie lo conocía, es totalmente difícil. Esto [marca líder] que es ya conocido y que vos ya sabés que tiene una trayectoria, no te digo que se vende solo, pero es como que tenés el camino bastante más allanado" (Entrevista 23, Técnico Comercial -TC-, 16/02/2019)

La representatividad de una marca líder genera prestigio y posicionamiento en el mercado. No obstante, la cartera de productos suele ser complementada con otras marcas líderes y/o productos genéricos más económicos, que en algunas ocasiones pueden representar la mayor parte de la facturación de la firma (Entrevista 19, TC, 22/06/2018 y Entrevista 20, TC, 25/06/2018). Independientemente de las marcas, las empresas locales concentran su facturación en la venta de agroquímicos (fungicidas, herbicidas, insecticidas) más que en la de semillas. Su fortaleza es el conocimiento de los productores locales y su trayectoria en el lugar, pues concentran su espectro de acción en la ciudad de Balcarce.

Las agronomías y acopios denominadas para este trabajo como regionales son sucursales de empresas que cuentan con una red de Centros de Servicios Integrales, cuyas casas centrales suelen estar en las localidades de origen o en otros centros urbanos de mayor relevancia territorial (Mapa 2)

MAPA 2

Red de centros de servicios de agronomías y acopios regionales

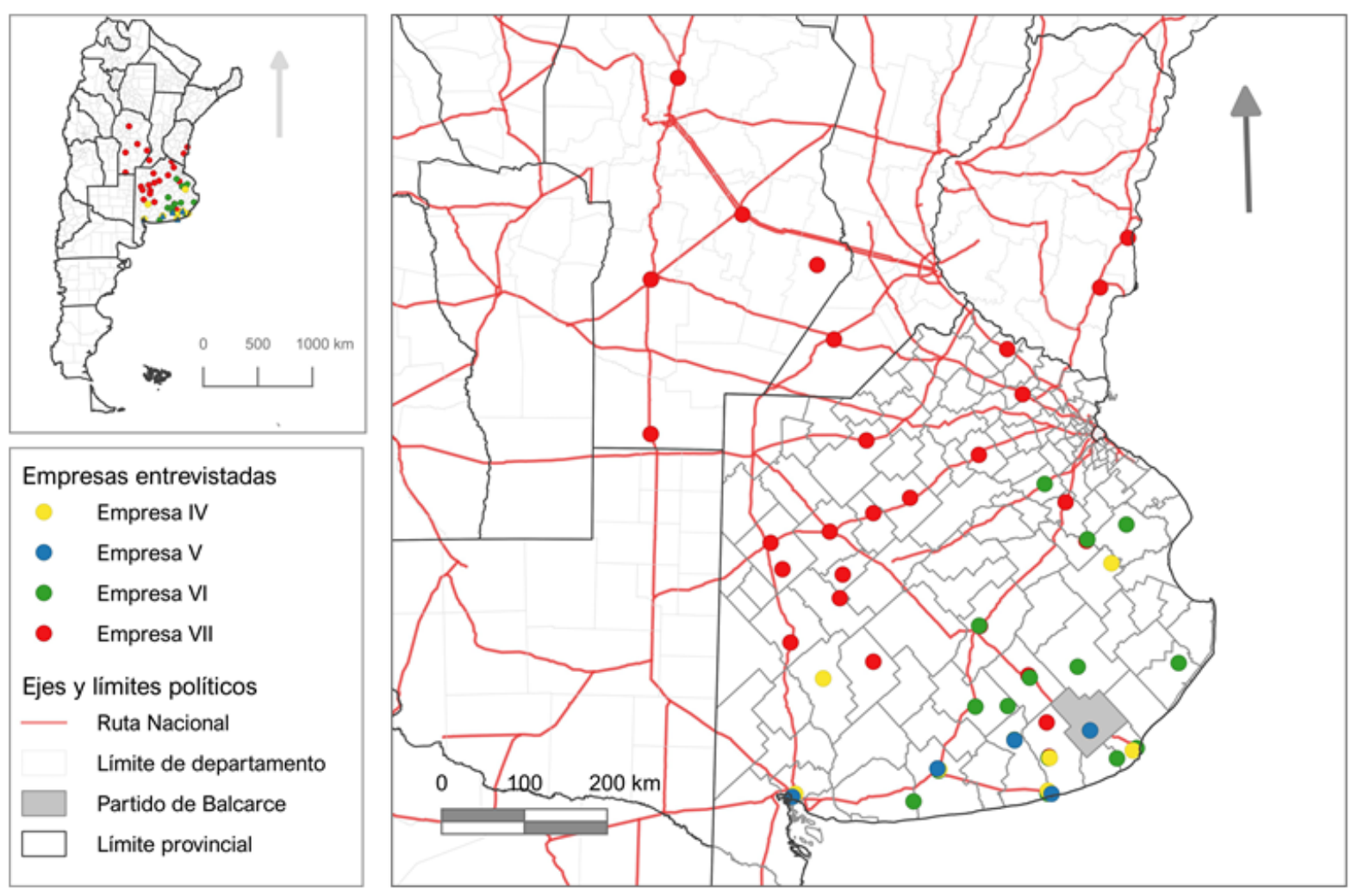

Fuente: Elaboración personal sobre la base de sitios web consultados y entrevistas implementadas entre junio 2018 y junio 2019. Cartografía INDEC 2010

En el interior de este grupo es posible distinguir distintos matices respecto del nacimiento, volumen de ventas, forma de organización de la empresa y diversificación de estrategias comerciales, productivas y financieras. Estas empresas se originaron a partir de Joint Venture (por ejemplo, Terramar JV SA), de fondos 
de inversión, pool de siembra o de megaempresas agropecuarias que, a partir de los años 2000 con el aporte de inversionistas privados, lograron diversificar sus estrategias empresariales (venta de maquinaria, servicios de financiamiento, siembras asociadas) y expandirse territorialmente (Ceres Tolvas) (Bassi et al., 2011). En algunos casos la participación de capitales financieros extranjeros les ha permitido trascender las fronteras nacionales, al establecer posiciones en países vecinos (Los Grobo) (Sosa, 2017).

A pesar de los matices y la complejidad que encierran estas empresas como ensamblajes en sí mismas, en este trabajo son estudiadas de acuerdo con sus prácticas desarrolladas en Balcarce. Asimismo, son agrupadas bajo una misma categoría en su carácter de extralocales y por su interacción con la administración central desde donde se comanda la gestión de la empresa. Éstas se posicionan en Balcarce principalmente desde el acopio y comercialización de granos y venta de agroinsumos. A diferencia de las agronomías locales, estas firmas pueden ser o no representantes exclusivos de las marcas líderes mundiales. En algunos casos, amplían y diversifican su cartera de productos con marcas propias de alimentos balanceados o agroquímicos.

Como se observa en la Tabla 1, tanto las agronomías como los acopios se especializan más en una actividad que en otra, ya sea la venta de agroquímicos (agronomías locales) o el acopio de granos (empresas regionales). Asimismo, la mayoría complementa su actividad principal con otras secundarias. Por ejemplo, algunos comercios entrevistados incursionan, en asociación con productores, en la producción de granos, conformando lo que en la jerga productiva se denominan siembras asociadas o "vaquita" (Grosso et al., 2009). También suelen multiplicar semillas autógamas (trigo y soja) para la empresa líder. Aquellas agronomías que tienen sus depósitos con una capacidad instalada mayor a la utilizada alquilan parte de ellos a grandes empresas, como McCain, y les ofrecen el servicio de logística.

Si bien son empresas que manejan grandes volúmenes de productos y de dinero, las tareas se realizan con un bajo número de personal. La Tabla 1 muestra que, para todos los comercios entrevistados, la mano de obra empleada no supera las 10 personas que trabajan de forma permanente. Las principales tareas a cargo de los empleados de agronomías y acopios están vinculadas con el asesoramiento, la venta de agroinsumos, la administración contable y la logística (depósito, distribución). El asesoramiento y la venta de insumos requieren de personal calificado con conocimiento en técnicas agronómicas (por ejemplo, momento y forma de aplicaciones de agroquímicos), y excelente relación y conocimiento de la diversidad de canales y estrategias comerciales. En general, estas labores son desarrolladas por ingenieros agrónomos y/o personal con expertise con altas capacidades para asesorar a los productores en el uso y compra de agroquímicos, o en comercializar granos, gracias a su trayectoria laboral en el rubro. La experiencia en ventas y la buena relación con los clientes es más valorada que el título universitario.

La destreza adquirida y la propia cartera de clientes fieles es el capital social con el que cuentan los encargados de las agronomías y acopios, y las habilidades más buscadas por las ET al momento de seleccionar el personal. Estas habilidades deben ser complementadas con el uso de herramientas de comunicación relacionadas con la IV Revolución Industrial, en la que las operaciones comerciales se realizan prácticamente online (Bensusán, Eichhorst y Rodriguez, 2017).

Sintetizando, el sector de agroinsumos y, en menor medida, el de acopio y comercialización de granos se expanden y consolidan en la década del 2000, con una mayor participación de empresas extralocales hacia el 2006. Las principales estrategias empresariales rondan entre representación exclusiva, asesoramiento y complementariedad con otras actividades como la producción de granos mediante siembras asociadas, la multiplicación de semillas y el alquiler de depósitos. La expansión de las agronomías y acopios, junto a la estrategia de representación exclusiva, no hacen más que reflejar las tendencias mundiales hacia la entrada en juego de nuevas firmas, la consolidación de las ya existentes y la concentración de la producción y comercialización de semillas y agroquímicos (Gorenstein y Ortiz, 2016). Sin embargo, el crecimiento de este sector no se traduce en la generación de nuevos puestos de trabajo, dado que son actividades poco intensivas en mano de obra. 


\section{3. ÁMBito DE LAS VERTICALIDADES: INTERACCIONES ENTRE LAS EMPRESAS TrANSNACIONALES Y LAS AGRONOMÍAS Y ACOPIOS LOCALIZADOS EN EL ÁREA DE ESTUDIO}

Si bien las interacciones sociales se desarrollan continuamente en el ámbito local, los intercambios de materialidades (agroquímicos, dinero, préstamos financieros, etc.) e inmaterialidades (información, afecto, confianza, etc.) son parte del ensamblaje global/local (De Landa, 2006). En este apartado se profundizará en las prácticas que tienen mayor incidencia en la interacción con las ET desde la noción de las verticalidades (Santos, 2000). Estas prácticas permiten observar cómo las empresas de bienes y servicios instaladas en Balcarce se conectan con otros puntos distantes a través de la circulación, el intercambio y el control, promoviendo y haciendo uso de una jerarquía de lugares. En ese sentido, las agronomías y acopios se convierten en vectores de las racionalidades establecidas por las ET. Las estrategias de dominación, que despliegan tanto las empresas líderes en el mercado de agroinsumos como las agronomías y acopios, son variadas y obedecen a captar cada vez más mercado en un espacio altamente competitivo.

Entre las principales estrategias se pueden mencionar aquellas relacionadas con la modalidad de las representaciones exclusivas, los mayores flujos de información, la incorporación de software específicos y las estrategias de marketing. Según los entrevistados, las firmas transnacionales productoras de agroinsumos (Syngenta, Corteva, Nidera, Basf, Bayer) tienden a posicionarse en las agrociudades con uno o dos representantes exclusivos. Si bien la tendencia es concentrar la venta en un solo representante local, uno de los entrevistados explica que:

"la tendencia era que haya uno solo [representante], pero hoy por hoy, casi todas las empresas tienen dos [representantes], porque con uno no pueden alcanzar a cubrir todo el espectro [de productores]. Es un negocio, donde hay mucha afinidad, mucha empatía de los dueños con los clientes y entonces con uno solo no pueden abarcar el $100 \%$ " (Entrevista 20, TC, 25/06/2018).

Las ET reconocen la importancia de los referentes locales en la comercialización de agroinsumos, para lograr insertarse en los territorios y captar mercado. Por ello los contactan e invitan a ser representantes exclusivos a nivel local/regional de los productos que elaboran o distribuyen.

La exclusividad impuesta por las ET es sinónimo de exigencias. Cada año, demandan a los comercios locales no sólo incrementar los volúmenes de ventas, sino también realizar un seguimiento de la actividad de los productores, recabando datos productivos (cantidad de hectáreas trabajadas, cultivos implantados y otros) y personales (fecha de cumpleaños, intereses, ocio y otros) de la cartera de clientes. Toda esta información es proporcionada por las agronomías y acopios a las ET, a través de un software específico para la gestión de las relaciones con los clientes, conocido como Customer Relationship Management (CRM). Las mismas ET proporcionan este software por medio del cual controlan toda la información disponible tanto de las agronomías como de los productores-clientes, como se expresa en el siguiente testimonio:

"Ellos [la ET] agarran, ellos tienen un detalle, de qué usa cada cliente de su producto, qué cantidad, cuánto, en qué lugar, todo detallado, yo tengo que pasar esa información todos los meses. ¿Entonces qué pasa? Cuando se termina el ciclo, si vos cumplís el objetivo hay una premiación hacia la agronomía” (Entrevista 19, TC, 22/06/2018)

El esfuerzo por lograr los objetivos es vivido por las agronomías o acopios como una usurpación a su autonomía en el negocio, sabiendo que no pueden modificar las reglas del juego. El sistema CRM recopila información de cada agronomía (número y nombre de clientes, cantidad de agroinsumos vendidos, acciones llevadas a cabo, relación entre cantidad de insumos comprados por hectáreas trabajadas para determinados cultivos) y a partir de ella la ET califica a sus distribuidores exclusivos y a los productores-clientes. Según el nivel de performance alcanzado, las agronomías reciben compensaciones, descuentos y bonificaciones en la compra de productos; o en el otro extremo, pueden perder la representación, como lo manifiesta el asesor técnico comercial de una de las agronomías: 
"Yo sé de algunas empresas, como por ejemplo (Marca de agroquímicos $\mathrm{x}$ ), que tenés ciertas exigencias de volumen de venta, y entonces vos tenés que salir a cumplir eso, para no perder esa representación, que por ahí, se la terminan dando a otro" (Entrevista 23, TC, 16/02/2019)

Reuniones periódicas con todos los representantes exclusivos son organizadas desde la ET para poner en conocimiento y competencia a las agronomías sobre la evolución global de las ventas de insumos y de la performance de cada una. Estas formas de acompañamiento, seguimiento y también control por parte de las ET son complementadas y retroalimentadas con Equipos Técnicos de la propia transnacional. Estos Equipos Técnicos, integrados por un gerente, llamado en algunos casos Joint Venture Manager (JVM), e ingenieros agrónomos especializados en el manejo agronómico de un determinado insumo, supervisan y monitorean a los encargados de las agronomías. Por medio de capacitaciones no sólo se busca dar a conocer los nuevos desarrollos biotecnológicos, sino que también se persigue alinear las perspectivas personales con la visión de la empresa (Sosa, 2017). A su vez, el monitoreo permanente les permite a las ET chequear la performance de sus representantes, y aproximarse al territorio y a quienes están a cargo de la producción primaria.

La exclusividad también implica adoptar nuevas formas de facturación y de pago. A las tradicionales formas de facturación por parte de la agronomía y a cuenta y orden de la ET, se le suma la facturación directa de esta última. Cuando la facturación está a cargo de la agronomía, el empresario local compra la mercadería y luego la vende y factura a su nombre. El sistema de cuenta y orden consiste en la puesta de mercadería en depósito de la agronomía en concesión y, una vez que se retira la mercadería, se liquida a la ET. Cuando los clientesproductores superan las 5.000 ha o compran grandes volúmenes de insumos, las mismas ET les facturan directamente. En estos casos, las agronomías pasan a ser meros depósitos de mercancías y/o en operadores logísticos. En Balcarce, las ET venden de manera directa a grandes empresas agropecuarias (como las estancias El Volcán y Cinco Cerros), pools de siembra, megaempresas (MSU, ADBlick, Espartina, Cazenave) y a la multinacional McCain para sus unidades de producción primaria propia.

Tanto la facturación a cuenta y orden como la facturación directa constituyen ventajas impositivas para las agronomías y acopios interesados en reducir el pago de impuestos, a la vez que prescinden de la propiedad de la mercancía puesta en depósito. A las ET estas modalidades les permiten simplificar el sistema de registros, pues administran pocas cuentas pero de grandes volúmenes (Fernández, 2018).

Respecto de los medios de pago, los más conocidos son pago al contado, cheque o depósito, canje de cereal y tarjeta rural. La tarjeta rural consiste en el pago de las compras de forma aplazada, pagando una cantidad fija cada mes, y es uno de los sistemas más difundidos en los últimos años, por los beneficios para compradores y vendedores. Al productor le permite pagar en pesos y el vendedor se asegura del cobro del importe de la factura.

Las ET contratan sistemas de seguros que monitorean la situación financiera de los productores. Estos sistemas permiten anticipar posibles cuentas impagas. Fue una situación recurrente en los años 90, que significó la quiebra de varias agronomías. Los sistemas de seguros financieros, sumados a los nuevos sistemas de facturación y medios de pago, garantizan cierta estabilidad financiera tanto a las agronomías y acopios como a las ET.

El uso de tecnología no sólo modifica las formas de gestión de las relaciones con los clientes, las formas de facturación y de pago, sino también las relaciones entre los gerentes de las ET y los encargados de las agronomías. Algunos de los sujetos entrevistados perciben negativamente el excesivo uso de las TIC en detrimento de las relaciones cara a cara. Al respecto, el dueño de una de las agronomías recuerda, con nostalgia, tiempos no muy lejanos en los que los vínculos humanos primaban sobre el uso de las tecnologías digitales:

"Lo que se perdió es la parte humana. Yo, hace 15 años, conocía a todos los gerentes [de las ET], a todos los que hacen la parte de desarrollo, los de marketing, conocíamos a todo el mundo, íbamos a reuniones de distribuidores y los conocíamos. Ahora, no. Salvo al representante tuyo de venta zonal y al jefe de esta gente, no conoces más a nadie. Se ha perdido el relacionamiento, se ha perdido el conocimiento de las caras...” (Entrevista 24, TC, 22/03/2019) 
Los flujos de información (datos productivos), bienes (agroinsumos) y capital financiero que circulan entre las ET, agronomías y acopios y los productores primarios constituyen vectores de las verticalidades. A través de estos flujos materiales e inmateriales, Balcarce como lugar de producción de granos se conecta con otros lugares tanto del mandar como del hacer. Estos flujos garantizan la globalización y homogenización de los procesos productivos, la jerarquización no sólo de los lugares sino también de las agronomías y acopios según su performance, y el control de los procesos productivos por parte de las ET y, por consiguiente, una mayor dependencia de los actores locales. A través de las estrategias señaladas de exclusividad, capacitaciones y monitorero por parte de los Equipos Técnicos, las ET transmiten sus ideales expresados en la misión y los valores de la firma, y logran la adhesión (Sosa, 2017) de las agronomías y acopios.

\section{ESCENARIO DE LAS HORIZONTALIDADES: LAS INTERACCIONES ENTRE LOS VENDEDORES DE AGROINSUMOS Y LOS PRODUCTORES}

Las representaciones exclusivas, la implementación de software para la circulación de información, los sistemas de seguros, las modalidades de facturación y de medios de pagos representan la racionalidad del orden establecido por las ET. En este apartado se indaga cómo dicha finalidad impuesta desde el exterior se inserta en el territorio a partir de las interacciones que se establecen entre los encargados de las agronomías y acopios y los clientes-productores. Se observan las prácticas que implementan los propietarios y/o gerentes de agronomías y acopios para contactar a los productores, fidelizar la relación comercial y difundir las innovaciones.

Las agronomías y acopios entrevistados buscan posicionarse en el mercado local y regional de agroinsumos utilizando diferentes estrategias para captar nuevos clientes. La mayoría de los entrevistados coinciden en que las estrategias de captación de clientes más utilizadas son el boca a boca, visita a campo o tranquerear, por su mayor eficacia. Uno de los vendedores de servicios explica la lógica del entramado de la comercialización:

"Porque si vos agarrás un padrón y llamas a un cliente que no te conoce, va a ser muy difícil que te venda [cereal] o que te preste atención. (...) A mí me lo demostró el tiempo, que uno puede llamar a 500 mil productores que uno no conoce, o pasar un precio 10 dólares arriba del mercado y no vas a hacer negocio” (Entrevista 21, TC, 22/06/2018).

La estrategia del boca a boca es la etapa inicial de un técnico comercial que recién se inicia en la actividad y que poco a poco se va haciendo conocido. Otra estrategia es participar en eventos locales y/o regionales, organizados por instituciones públicas (INTA, FCA-UNMDP) y privadas (AAPRESID), y de esta manera hacerse visible a los ojos de los posibles clientes. Para quienes ya cuentan con trayectoria en el rubro, el camino se encuentra más allanado. Así, comenta uno de ellos que

"por el hecho de haber tenido una trayectoria a nivel local, la gente conoce tu forma de ser y tu forma de trabajar. Vos ahora vas bajo el nombre de una empresa y bajo ciertas normativas, precio y condiciones. Entonces vos, como persona, ya tenés el vínculo establecido" (Entrevista 23, TC, 16/02/2019)

En menor medida, la localización estratégica de la agronomía en las avenidas y rutas principales que atraviesan la ciudad contribuye a captar potenciales clientes en tránsito. Uno de los técnicos-comerciales comenta que

“estas cosas se venden solas y te acercan a vos un montón de clientes de forma directa o indirectamente. No solamente los que vos ya tenés incorporados como clientes, sino que uno pasa por la ruta y decís 'Ahh, estos venden [marca líder], paro acá... yo necesito'...” (Entrevista 23, TC, 16/02/2019)

Una vez captados los clientes, se busca fidelizar la relación con productores y empresas agropecuarias a través del asesoramiento, organización de charlas, capacitaciones y el trabajo responsable. El asesoramiento implica que los técnicos-comerciales de las agronomías estén disponibles en todo momento y lugar para responder a las consultas de los productores. Las agronomías terminan convirtiéndose en el grupo asesor del productor, y sus empleados junto al Equipo Técnico de las ET brindan soluciones integrales. 
Sin embargo, se observan ciertas resistencias a las recomendaciones del técnico comercial, principalmente entre los productores más tradicionales, de edad avanzada y orientados a la producción de papa. Un encargado de una agronomía explica:

"El papero es muy 'yo', es muy 'hago lo que yo sé', es muy 'yo tengo la receta, y es así'. Y no le cambiás la cabeza; y de una persona de 50 años para arriba, menos. 'La vengo haciendo así la chacra. No me vas a venir a decir vos lo que tengo que poner, si yo vengo haciendo hace 30 años, desde los 18 años que hago chacra de papa con mi papá '”. (Entrevista 22, TC, 08/08/2018)

El testimonio da indicios de que existen algunas reacciones no conformistas a las innovaciones recomendadas por los técnicos-comerciales de las agronomías y acopios. Pareciera que no resulta tan sencilla la difusión y adopción de nuevas técnicas agronómicas promovidas por los voceros de las ET; sin embargo, estas resistencias no logran generalizarse e instaurar el conflicto en relación con el modelo dominante.

Ante la necesidad de difundir las innovaciones y mantener, e incluso incrementar, los volúmenes de venta, los técnicos-comerciales de las agronomías y acopios implementan de forma continua diferentes acciones de promoción y marketing sobre nuevos insumos y técnicas agronómicas. Por ejemplo, desarrollar lotes demostrativos o jornadas a campo. En varias ocasiones, estos eventos se organizan junto a especialistas de las ET e investigadores de las instituciones públicas de ciencia y técnica: son charlas con los productores en las que se dan a conocer nuevos productos y nuevas técnicas de aplicación de agroquímicos y control de plagas. No siempre las convocatorias tienen éxito, dadas las dificultades que implica que todos los actores puedan coincidir en tiempo y lugar. Por ello, algunos entrevistados indican que la modalidad más exitosa para los fines comerciales es el trato personalizado con el productor:

"Si invitábamos a 50, venían 8. Y eso no nos servía. Entonces, preferíamos visitas a campo: ‘¿mañana vas a estar en el campo?', 'sí', 'bueno, listo, nos tomamos unos mates'. Y era más productivo hacer ese puerta a puerta que hacer una reunión.” (Entrevista 22, TC, 08/08/2018).

La fidelización del cliente también se alcanza trabajando responsablemente y respondiendo a sus demandas. En varias ocasiones se requiere interactuar con otras agronomías para cumplir con las peticiones de los clientes. Es común que existan intercambios de productos complementarios para evitar perderlos, tal como lo comenta el técnico comercial:

“Nosotros muchas veces canjeamos. Por ahí yo te digo: 'De [ET x], yo semillas no tengo' pero yo sé que hay otro que tiene, lo llamo y me vende y yo le vendo. Por ahí un productor que no quiere ir a ese lugar a comprarla, me la compra a mí y yo se la pido a él. Entonces hacemos canje, de mercadería: yo te doy tanta mercadería y él me da otra y hacemos compensaciones". (Entrevista 22, TC, 08/08/2018)

Si bien las relaciones cara a cara, el conocimiento y la confianza siguen siendo claves para vender un producto, una vez que se establece un vínculo entre las agronomías y acopios con los productores -al igual que lo observado en el apartado anterior entre las ET y las agronomías y acopios- es cada vez más frecuente el uso de las TIC. En la era de la IV Revolución Industrial, los nuevos dispositivos móviles permiten acercar al productor y a los oferentes de servicios a través de plataformas digitales e internet. Los actores se encuentran conectados en todo tiempo y lugar, las distancias se reducen y los límites entre el lugar de trabajo, de descanso y del hogar se diluyen (Bensusán et al., 2017). Cada vez más las operaciones se llevan a cabo vía Whatsapp o llamadas telefónicas. Asimismo, las tecnologías posibilitan una mayor coordinación de las actividades que competen tanto a la agricultura como a las empresas que venden agroinsumos. En contrapartida, se reducen los encuentros, los tiempos compartidos, los mates de oficina. El dueño de una agronomía explica cómo utiliza las TIC: "Hoy, con los Whatsapp, te perdés el ida y vuelta con el cliente. Me parece a mí que eso es importante, entiendo que hoy cambió. Antes el productor venía al negocio a charlar, a tomar mate. Hoy ya no existe más eso. No existe más." (Entrevista 24, TC, 22/03/2019). 
Estas expresiones de nostalgia sobre la relación personal se observan con mayor frecuencia en empleados de más de 40 años, que todavía hallan en las relaciones cara a cara potencialidades de encuentro e intercambio mucho más enriquecedoras que las relaciones virtuales. De todas maneras, jóvenes y adultos, con experiencia, basan sus vínculos con clientes y proveedores a través de relaciones de confianza previas. El uso de las TIC no es compatible con la falta de relaciones de empatía previas.

Como se indicó anteriormente, las agronomías y acopios suelen diversificar sus actividades mediante la celebración de siembras asociadas. Estas formas de asociación entre distintos sujetos sociales agrarios se diferencian de los fondos de inversión, en que los productores y contratistas, se constituyen como socios y, por lo tanto, se comprometen con la actividad. Esta modalidad está principalmente desarrollada por los acopios, denominados en el presente trabajo de carácter regional (Empresas V y VI). En el caso de la Empresa V, las Siembras Asociadas pueden adoptar distintas modalidades, dependiendo del número de actores involucrados y sus formas de vinculación. Un ejemplo es cuando se asocia un productor que aporta el capital tierra, otro sujeto el capital trabajo y la empresa todos los insumos. A pesar de la diversidad de formatos asociativos, en general la Empresa V lleva adelante la administración de las siembras y, por lo tanto, de la gestión de los contratos. Con esta estrategia la firma se propone como misión contribuir al crecimiento, la diversificación productiva y la expansión territorial de los pequeños y medianos productores, y evitar la competencia en el mercado de tierra entre ambos actores. Se reconocen como promotores del desarrollo de los actores locales, diferenciándose de los pools de siembra extralocales (Entrevista 23, TC, 16/02/2019).

Las interacciones que mantienen las empresas entrevistadas con los productores a través de la compra-venta de insumos agropecuarios y las estrategias de captación y fidelización de los clientes determinan el ámbito de las horizontalidades (Santos, 2000). Si bien es difícil delimitar este ámbito de acción por la complejidad de relaciones que se establecen entre la tenencia de la tierra y el lugar de residencia de los productores (algunos productores compran en Balcarce porque residen en la ciudad, pero tienen explotaciones en el partido y fuera de él; otros residen en otras localidades, pero producen y compran en Balcarce), en general las empresas entrevistadas trabajan en zonas cerradas. Esto significa que las ET autorizan a sus representantes exclusivos a vender sus productos sobre un área de proximidad delimitada. En caso de operar fuera de ésta, los encargados y técnicos comerciales de las agronomías deben explicitar las razones que justifiquen la venta frente a la ET.

"Cada vez que nosotros tocamos clientes de otra zona tenemos que explicar por qué nos metimos en esa zona. Si es porque el cliente tiene afinidad con nosotros, si es un cliente mantenido, que por ahí lo tenemos hace muchos años, o explicar el porqué. (Entrevista 19, TC, 22/06/2018).

Teniendo en cuenta la información proporcionada por las agronomías y acopios entrevistados, el radio de acción de la mayoría de las firmas abarca los partidos de Balcarce, General Pueyrredon, General Alvarado, Lobería, Mar Chiquita y Necochea. Sólo dos de las firmas (V y VII) también mencionaron los partidos de Maipú, Olavarría, Tandil y Azul (Mapa 3). 
MAPA 3

Área de influencia de las acciones de las agronomías y acopios de Balcarce entrevistados
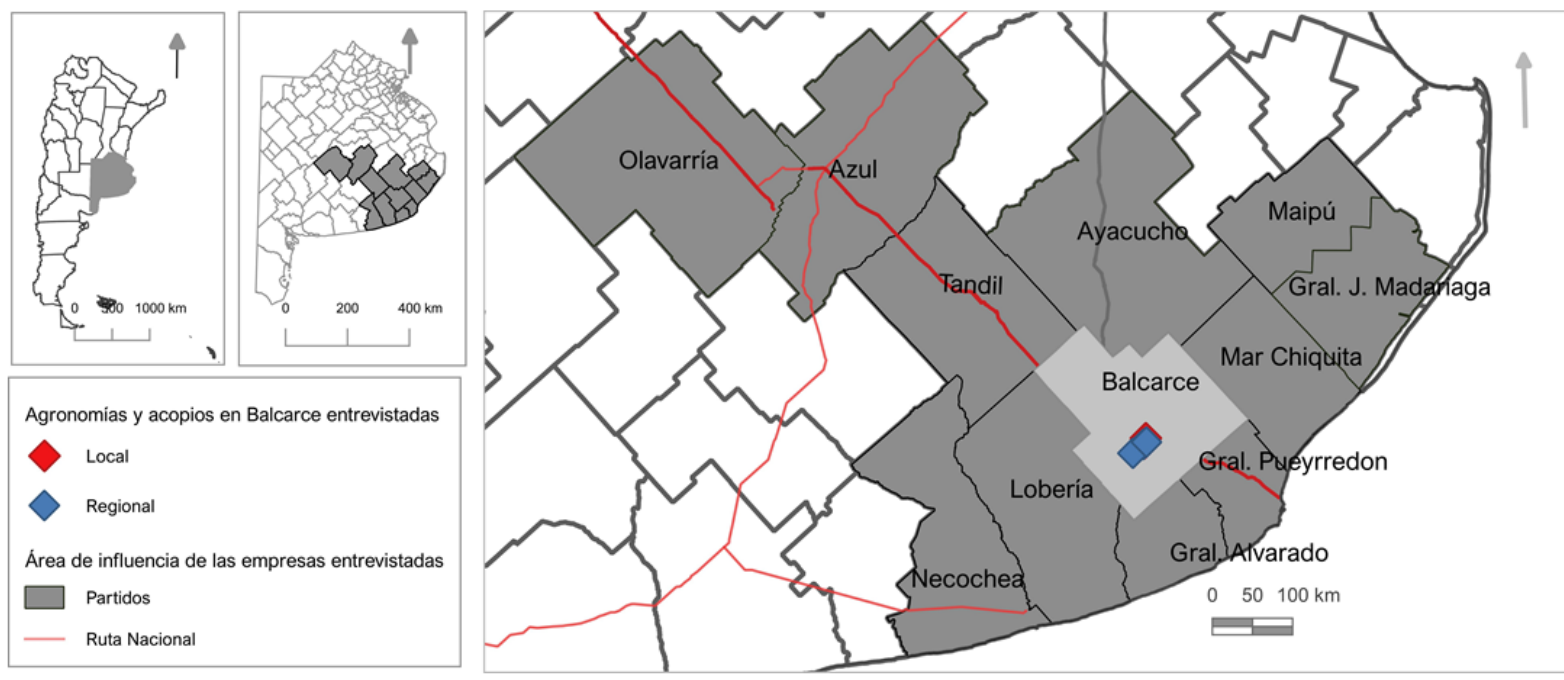

Fuente: Elaboración personal sobre la base de sitios web consultados y entrevistas implementadas entre junio 2018 y junio 2019. Cartografía INDEC 2010

En síntesis, los espacios horizontales se construyen en el día a día, y se transforman al ritmo de los cambios en el contexto. Las estrategias desplegadas por los actores para captar y fidelizar clientes, y para promocionar innovaciones, combinan antiguas y tradicionales prácticas, como el contacto cara a cara, tranquerear, el boca a boca, con nuevas estrategias lideradas por las TIC, con el fin de generar un espacio de confianza, en el cual en varias ocasiones la empatía supera los beneficios económicos. El trabajo de campo realizado en Balcarce, observando la vida cotidiana de las agronomías y acopios, muestra que algunos vendedores van siguiendo el crecimiento de sus clientes, con lo que adquieren experiencia en ventas y fortalecen su propio perfil profesional. Las prácticas reconocidas para este trabajo de fidelización evidencian procesos de construcción de alianzas entre los diferentes actores (entrevistados, ET, productores), a fin de legitimar el modelo de agronegocio y hacer del discurso, transmitido en las diferentes acciones (jornadas, capacitaciones), un consenso (Córdoba, 2014).

\section{DiSCUSIÓN Y REFLEXIONES FINALES}

Este trabajo visibiliza y pone en discusión el rol que cumplen los acopios y las agronomías en la construcción del territorio, en la interacción entre lo local y lo global y en la inserción de las ET en Balcarce. Bajo las nociones de horizontalidades y verticalidades se indagó sobre las prácticas sociales que incumben a las empresas entrevistadas, firmas elaboradoras de agroinsumos, y sus relaciones con los productores de la zona.

Una primera conclusión clave es que las lógicas de las empresas transnacionales y las estrategias de captación, fidelización y promoción -desarrolladas por los técnicos comerciales de las empresas entrevistadasposicionan a las agronomías y acopios como actores clave en la intermediación entre las ET y los productores primarios, y, por ende, en la relación local - global. Así, las agronomías y acopios constituyen la puerta de entrada a las empresas extralocales de agroinsumos.

En segundo lugar, se observa que la relación histórica con los productores pequeños y medianos (a través de la amistad, el parentesco y la fidelidad), la trayectoria comercial y el conocimiento del territorio son los elementos claves que permiten a los gerentes y administradores de las agronomías y acopios cumplir con su rol de intermediarios eficaces entre lo local (productores) y las ET. 
En tercer lugar, se observa que las ET se fueron apropiando de estas relaciones de confianza construidas históricamente. De esta manera, actualmente las ET pueden interactuar de manera directa con los productores primarios, porque el volumen de compra lo amerita, por el accionar de los Equipos Técnicos o porque cuentan con toda la información de la cartera de clientes pertenecientes a los acopios y agronomías locales.

En cuarto lugar, un elemento clave en la construcción de esta relación entre empresas productoras y ET es, tal como lo señala Diego Fernández (2018), la simplificación de la administración . Los sistemas de seguros y las modalidades de facturación y medios de pago garantizan una administración financiera eficaz y evitan riesgos empresariales. La facilitación de los procesos burocráticos es aún mayor con las empresas productoras más grandes, pues la relación se establece directamente con las ET. Esto conlleva una mayor concentración y volumen de las operaciones y, por ende, define un rol cada vez más clave de las ET en los territorios, por el control que ejercen en la producción y en los negocios. Así, se observa cómo la información, la tecnología y la gestión se ponen a disposición de las empresas transnacionales, con lo que cambian las relaciones de poder entre los actores (Santos 1996, 2000).

En quinto lugar, a través de las Siembras Asociadas productores y agronomías comparten riesgos empresariales. Si bien esta modalidad permite a las agronomías fidelizar las relaciones con los productores, lo cual obedece a una lógica empresarial clave, permite, por otro lado, sostener la actividad productiva de muchos pequeños y medianos productores, lo que evita la competencia con las megaempresas agropecuarias.

Otro tema clave es que las ET invierten altos porcentajes de su facturación en el área de Innovación y Desarrollo (I \& D) en nuevas variedades de semillas, principios activos y eventos biotecnológicos, y llevan a cabo ensayos en diferentes áreas, cuyos resultados son divulgados entre los dueños/encargados y empleados de las agronomías o acopios exclusivos. A su vez, éstos son los encargados de difundir esta información en el territorio. El asesoramiento diario de los profesionales dentro de las ET, como los de las agronomías y acopios, es un excelente medio para difundir innovaciones, y de alguna manera desplaza a las tradicionales instituciones públicas de investigación y desarrollo. Esto coincide con lo observado por Astegiano (2015) y Finola y Maldonado (2017) para la provincia de Córdoba, donde determinadas ciudades se convierten en plataformas de innovaciones técnicas para la producción agropecuaria a partir de la acumulación/concentración de las empresas proveedoras de insumos. Ello invita a reflexionar sobre el rol de las instituciones públicas de ciencia y técnica, y sobre los desafíos para el futuro.

Una mirada diacrónica sobre las relaciones verticales y horizontales analizadas permite observar cambios y continuidades en el accionar de los actores en el territorio. Los cambios operados a nivel mundial dentro del contexto de la globalización han repercutido fuertemente en el sector agropecuario y han incrementado la competencia en el mercado de agroinsumos. Las ET atraviesan constantes procesos de fusiones y adquisiciones, y concentran cada vez más el comercio de agroinsumos en pocas firmas (Grupo ETC, 2019). Estos cambios se territorializan en cada una de las agrociudades como Balcarce. Las agronomías y acopios se expanden en número, a la vez que experimentan cambios en su relación con las ET. A los tradicionales objetivos de ventas, se suman nuevas exigencias expresadas en normas y requisitos sobre cómo comercializar e intercambiar información de los clientes ganados por los locales, como también acompañar en el servicio de posventa. Los mismos entrevistados locales reconocen la pérdida de autonomía para manejar sus estrategias comerciales, pues son meros representantes de los intereses de las ET. Si bien se ha visto incrementar el número de agronomías y acopios a inicios del nuevo milenio, la tendencia es concentrar, aún más, el mercado de agroinsumos y la disminución de los representantes exclusivos.

El trabajo de campo comprueba que las verticalidades y horizontalidades (Santos, 2000) trascienden cualquier tipología de empresas que se pudiera establecer. Las prácticas observadas evidencian que tanto las agronomías locales como las regionales se ven atravesadas por la racionalidad comercial de los sectores hegemónicos. Estas lógicas globales son reproducidas en las horizontalidades, en las que no se manifiesta ningún tipo de cuestionamiento a las formas de producción hegemónicas. La modernización asociada 
con el uso de paquetes tecnológicos altamente dependiente de insumos (semillas, herbicidas, insecticidas, fertilizantes) es una bandera que la mayoría de los productores agropecuarios, académicos y técnicos pareciera haber adoptado como el único remedio para sobrevivir en una creciente competencia global de producción de alimentos. En síntesis, este ensamblaje de heterogéneos y múltiples actores, en el que interactúan materialidades e inmaterialidades, reconfigura y consolida una red socio-técnica-productiva asociada al modelo hegemónico agrario mediante el consenso, la legitimación y la complacencia. Esta cultura de la modernización y el aumento de la productividad subyace inconscientemente en el accionar de los entrevistados, y claramente garantiza una metamorfosis, desde el punto de vista de los autores del presente trabajo, silenciosa, de espacio habitado.

\section{ReFERENCIAS}

Albaladejo, C. (2013). Dinámica de la inserción territorial de la agricultura pampeana y emergencia del agrobusiness. En Gras, C. y Hernández, V. (Coords.), El agro como negocio: producción, sociedad y territorios en la globalización (pp. 67-95). Buenos Aires: Biblos.

Astegiano, N. (2015). Red de agronegocios en el norte de la provincia de Córdoba. Revista Síntesis, 6. Recuperado de https://revistas.unc.edu.ar/index.php/sintesis/article/view/16148

Bassi, N., Iorio, C. y Cendón, M. L. (2011). Lógica de Funcionamiento de un Pool de Siembra Local. VII Jornadas Interdisciplinarias de Estudios Agrarios y Agroindustriales. Centro Interdisciplinario de Estudios Agrarios. Buenos Aires. Recuperado de http://www.ciea.com.ar/jornadas-anteriores/vii-jornadas-interdisciplinarias-de-e studios-agrarios-y-agroindustriales-2011/

Bensusán, G., Eichhorst, W. y Rodriguez, J. M. (2017). Las transformaciones tecnológicas y sus desafios para en empleo, las relaciones laborales y la identificación de la demanda de cualificaciones. Santiago de Chile: CEPAL - Naciones Unidas. Recuperado de https://repositorio.cepal.org/bitstream/handle/11362/42539/S1700870_es.pdf?sequ ence $=1$ \&isAllowed $=y$

Bisang, R., Anlló, G., Campi, M. y Albornoz, I. (2009). Cadenas de valor en la agroindustria. En: Kosacoff, B. y Mercado, R. (Eds.), La Argentina ante la nueva internacionalización de la producción. Crisis y oportunidades (pp. 218-276). Buenos Aires: CEPAL - PNUD.

Bruno, M., Mujica, G., Cendón, M. L. y Viteri, M. L. (2018). Innovaciones en la trama productiva - comercial de papa en el sudeste de la Provincia de Buenos Aires, Argentina. X CONGRESO ALASRU Ruralidades en América Latina: Convergencias, disputas y alternativas en el siglo XXI. Montevideo.

Bruno, M., Viteri, M. L. y Sili, M. (2018). Multiplicidad de actores en la construcción de territorios urbanos-rurales: el rol de las empresas comercializadoras de agro-insumos y granos. X Congreso ALASRU. Ruralidades en América Latina: Convergencias, disputas y alternativas en el siglo XXI. Montevideo.

Carabajal, M. I. (2013). Transnacionalización Agropecuaria y Reconfiguraciones Territoriales. KULA. Antropólogos del Atlántico Sur, 9, 47-57. Recuperado de http://www.revistakula.com.ar/7-carabajal/

Cauhèpè, M. y Gutheim, F. (2013). Agricultura y ganadería pampeanas. Mar del Plata: EUDEM.

Córdoba, M. S. (2014). Ensamblando actores. Una mirada antropológica sobre el tejido de alianzas en el universo del agronegocios. Working Paper Series, 68. Recuperado de https://www.desigualdades.net/Resources/Working_P aper/68-WP-Cordoba-online.pdf

De Landa, M. (2006). A New Philosophy of Society. Assemblage Theory and Social Complexity. Londres Nueva York: Continuum.

Fernández Martínez, H. (24 de septiembre de 2018). Mercados: La soja en los valores más bajos de 10 años, quizás sean tiempos del ansiado rebote. Clarín. Recuperado de https://www.clarin.com/rural/soja-bajos-10-anos-tiemposansiado-rebote_0_nGbHdXF6H.html 24/09/2018

Fernández, D. (2018). El desierto verde. Sobre el proceso de concentración de la agricultura pampeana. Buenos Aires: Imago Mundi. 
Finola, A. y Maldonado, M. I. (2017). Ciudad y modernización agropecuaria. Río Cuarto como plataforma para la territorialización de las transformaciones agropecuarias. Boletín de Estudios Geográficos, 107, 21-50. Recuperado de https://bdigital.uncu.edu.ar/9315.

Gorenstein, S. y Ortiz, R. (2016). Empresas transnacionales en la agricultura y la producción de alimentos en América Latina y el Caribe. Documento de Trabajo. Buenos Aires: Fundación Foro Nueva Sociedad (NUSO). Recuperado de https://www.nuso.org/media/documents/Analisis_Gorenstein.pdf

Gras, C. y Hernandez, V. (2013). El agro como negocio: producción, sociedad y territorios en la globalización. Buenos Aires: Biblos.

Grosso, S., Arrillaga, H., Bellini, M., Qüesta, L., Guibert, M., Lauxmann, S. y Rotondi, F. (2009). Impactos de los pools de siembra en la estructura social agraria y en la gestión de la agricultura. Una aproximación a las transformaciones en el centro de Santa Fe. VI Jornadas Interdisciplinarias de Estudios Agrarios y Agroindustriales. Facultad de Ciencias Económicas, Universidad de Buenos Aires. Buenos Aires.

Grupo ETC (2019). Tecto-fusiones comestibles. Mapa del poder corporativo en la cadena alimentaria. Recuperado de h ttps://www.etcgroup.org/sites/www.etcgroup.org/files/files/etc_platetechtonics_nov_spanish-fin.pdf

Hernández, V. (2015). Empresas, innovaciones y mercado de agroinsumos, del productor al consumidor. Revista de Ciencias Sociales, 28(36), enero-junio, 99-120. Recuperado de http://biblioteca.clacso.edu.ar/Uruguay/ds-unr/ 20160711105935/2015-36.pdf

INDEC (Instituto Nacional de Estadísticas y Censos) (2010). Clasificador Nacional de Actividades Económicas (CLANAE 2010). Notas Metodológicas.

Long, N. (2007). Sociología del desarrollo: una perspectiva centrada en el actor. México D. F.: Centro de Investigaciones y Estudios Superiores en Antropología Social.

Maldonado, G. (2019). Territorio y agriculturización en Argentina. Objetos, acciones y aconteceres. Estudios Rurales, 9(17), 164-197. Recuperado de http://ppct.caicyt.gov.ar/index.php/estudiosrurales/article/view/14122/4545 4575768163

Massey, D. (2012). Espacio, lugar y política en la coyuntura actual. Urban, $0(04), 7-12$. Recuperado de http://polire d.upm.es/index.php/urban/article/view/1864/2117

Mateos, M. (2003). Documento 15:papa prefrita congelada. Componentes macroeconómicos, sectoriales y microeconómicos para una estrategia nacional de desarrollo. Lineamientos para fortalecer las fuentes de crecimiento económico. Ministerio de Economía de La Nación, Secretaría de Política Económica, Unidad de Preinversión (Argentina). CEPAL (Argentina). IICA (Argentina). Recuperado de https://repositorio.iica.int/bitstream/handle/11324/ 18177/CDAR21087993e.pdf?sequence $=1$

Mosciaro, M. (2011). Caracterización de la Producción y Comercialización de Papa en Argentina. Área de Economía y Sociología Rural. EEA INTA Balcarce. Recuperado de https://inta.gob.ar/documentos/caracterizacion-de-la-p roduccion-y-comercializacion-de-papa-en-argentina

RedAgrícola (2019). Digital Farming: Donde todos los grandes quieren estar. Recuperado de https://www.redagricola .com/cl/digital-farming-donde-todos-los-grandes-quieren-estar/

Romero, G. F. (2014). Los agroquímicos: concentración y dependencia en la Argentina (1976-2014). Revista Interdisciplinaria de Estudios Agrarios, 41. Recuperado de http://www.ciea.com.ar/web/wp-content/uploads/ 2016/11/RIEA-41-03.pdf

Santos, M. (1996). Metamorfosis del espacio habitado. Barcelona: Oikos Tau

Santos, M. (2000) La naturaleza del espacio. Técnica y tiempo. Razón y emoción. Barcelona: Ariel.

Saquet, M. A. (2015). Por una geografía de las territorialidades y las temporalidades: Una concepción multidimensional orientada a la cooperación y el desarrollo territorial. La Plata: Universidad Nacional de la Plata. Facultad de Humanidades y Ciencias de la Educación. Recuperado de http://www.libros.fahce.unlp.edu.ar/index.php/libr os/catalog

Sili, M. (2018). La acción territorial. Una propuesta conceptual y metodológica para su análisis. Revista Brasileira de Estudos Urbanos e Regionais, 20(1), 11-31. 
Silveira, M. (1997). Territorio de las verticalidades y horizontalidades: una propuesta de método. Sexto Encuentro de Geógrafos de América Latina, Buenos Aires.

Sosa, A. P. (2017). El papel de las megaempresas agropecuarias en la financiarización del régimen alimentario global. Los casos del Grupo Los Grobo y El Tejar en Argentina y en Brasil (1996-2015) (Tesis doctoral). Facultad de Ciencias Sociales, UBA, Buenos Aires-Université de Toulouse 2 - Jean Jaurès, Toulouse.

Teubal, M., Domínguez, D. y Sabatino, P. (2005). Transformaciones agrarias en la Argentina. Agricultura industrial y sistema agroalimentario. En N. Giarracca et al. (Ed.). El campo argentino en la encrucijada. Estrategiasy resistencias sociales, ecos en la ciudad (pp. 39-78). Buenos Aires: Alianza.

Zavaleta, A. (2014). Distribución de agroinsumos al mercado agropecuario argentino. El caso Dow Agroscience (Tesis de grado). Universidad de San Andrés, Victoria, Argentina. Recuperado de http://hdl.handle.net/10908/10839

\section{Notas}

1 De un total de 110 firmas, un $58 \%$ se dedica a la comercialización de bienes (Agronomías y Acopios; Venta de Maquinaria Agrícola, Veterinaria; Venta de Combustibles y Consignatarios de Hacienda), 21 \%, a la industria manufacturera (Fabricación de bombas de agua, maquinaria de pos-cosecha, silos, implementos agrícolas, plaguicidas, alimentos balanceados), el $15 \%$, a servicios directos al sector primario (Monitoreo y Control de Plagas, Acondicionamiento y Frigorífico para Papa, Cabañas Reproductoras y Producción de Semillas) y el 6 \% restante, a servicios profesionales y técnicos (Servicios de Ensayo, Laboratorio de Semillas y Suelos). 